\title{
Effects of a synbiotic yogurt using monk fruit extract as sweetener on glucose regulation and gut microbiota in rats with type 2 diabetes mellitus
}

\author{
Qingfeng Ban, ${ }^{1,2} \odot$ Jianjun Cheng, ${ }^{1 *}$ Xiaomeng Sun, ${ }^{1} \odot$ Yunqing Jiang, ${ }^{1,2}$ Shanbo Zhao, ${ }^{1,2}$ Xiao Song, ${ }^{1,2}$ \\ and Mingruo Guo ${ }^{2,3 *}$ \\ ${ }^{1}$ College of Food Science, Northeast Agricultural University, Harbin, 150030, China \\ ${ }^{2}$ Key Laboratory of Dairy Science of Ministry of Education, Northeast Agricultural University, Harbin, 150030, China \\ ${ }^{3}$ Department of Nutrition and Food Sciences, College of Agriculture and Life Sciences, University of Vermont, Burlington 05405
}

\begin{abstract}
We developed a synbiotic yogurt using monk fruit extract as a sweetener and investigated the effects of feeding the yogurt to rats with type 2 diabetes induced by streptozotocin and a high-fat diet. The rats fed the synbiotic yogurt showed greater blood glucose regulation and a significant decrease in insulin resistance and glycosylated hemoglobin compared with rats fed yogurt sweetened with sucrose, and they showed a remarkable improvement in short-chain fatty acid levels and gut microbiota status. Liver and kidney damage was also ameliorated in the rats fed the synbiotic yogurt. Immunohistochemistry analysis showed that the synbiotic yogurt inhibited $\beta$-cell loss compared with the control yogurt. Consuming the synbiotic yogurt helped to restore the islets of Langerhans. Our results indicated that monk fruit extract may be a good alternative to sucrose for synbiotic yogurt products in people with type 2 diabetes to delay the progression of diabetes and associated complications.
\end{abstract}

Key words: synbiotic yogurt, monk fruit extract, gut microbiota, type 2 diabetes mellitus

\section{INTRODUCTION}

Diabetes mellitus is one of the largest global health problems of the 21st century (World Health Organization, 2009). Type 2 diabetes mellitus accounts for over $90 \%$ of all cases of diabetes and is a chronic illness of the endocrine system. Uncontrolled, diabetes is associated with various acute and chronic comorbidities (Chakrabarti and Rajagopalan, 2002; Umar et al., 2010). Type 2 diabetes usually occurs in adults but

Received October 3, 2019.

Accepted December 18, 2019.

*Corresponding authors: cheng577@163.com and mguo@uvm.edu the age of onset has been lowered in recent years. In type 2 diabetes, the body can still produce insulin, but is resistant to it, leading to insulin failure. Long-term insulin resistance may lead to insufficient insulin secretion, and insulin resistance and insulin deficiency lead to hyperglycemia. (Fox et al., 2015). According to the International Diabetes Federation, 425 million people (20 to 79 years old) had diabetes worldwide in 2017, or 1 in 11 adults. That number is estimated to increase to 700 million by 2045 (International Diabetes Federation, 2017). One study showed that metabolic changes, including hyperlipidemia, hypertension, insulin resistance, and increased adiposity, were associated with changes in the composition of the gut microbiota (Vijay-Kumar et al., 2010). Initial data have shown differences in the composition of the adult intestinal microbiota between people with diabetes and controls (Larsen et al., 2010; Qin et al., 2012). These factors have also been highlighted as triggers for the development and progression of type 2 diabetes and its complications (Stephens et al., 2009; Larsen et al., 2010). Consequently, finding a fast and effective approach to preventing and treating type 2 diabetes is necessary. At present, many prevention and treatment options are available to manage this disease, including specially designed foods.

Yogurt is a source of protein ( $8.5 \mathrm{~g}$ per cup) that contains all 9 essential amino acids (USDA, 2019), but an important concern related to the intake of dairy products is the fact that most low-fat dairy products, yogurts in particular, are high in added sugar to improve their taste (Gijsbers et al., 2016). Excessive sugar intake has been identified as one of the primary causes for increased risk of type 2 diabetes and obesity (Howard and Wylie-Rosett, 2002; Murphy and Johnson, 2003), driving demands for sugar reduction, such as replacement with low- or no-calorie alternative sweeteners.

Siraitia grosvenorii is a perennial vine of the Cucurbitaceae family, and its fruit is commonly known as monk fruit (Luohanguo; Lu and Zhang, 1984). Monk 
fruit has been shown to have certain health benefits, including antitussive, anti-asthmatic, antioxidative, liver-protective, glucose lowering, immunoregulation, and possibly anticancer properties (Wang et al., 2010). The major sweetening compounds in the fruit are terpene glycosides called mogrosides. The most abundant compound is mogroside $\mathrm{V}$, which is 250 to 400 times sweeter than sucrose (Takasaki et al., 2003). Monk fruit extract (MFE) has been used as a non-nutritive sweetener and flavor enhancer in the United States, China, and Japan, and it is a safe and suitable low-calorie sweetener for people with type 2 diabetes (Qi et al., 2008; Zhou et al., 2009; Xu et al., 2015; Zhou et al., 2018). It also has promising pharmacological functions related to reducing blood glucose (Qi et al., 2006; Zhou et al., 2009; Shi et al., 2014; Liu et al., 2019).

Monk fruit extract has been used widely in functional beverages, but very limited information is available about the effects of MFE-fortified foods in type 2 diabetes. In this study, we developed a synbiotic yogurt using MFE as a sweetener. The objective of this study was to investigate the effects on glucose tolerance, insulin resistance, and gut microbiota of feeding the synbiotic yogurt to rats on a high-fat diet and with streptozotocin (STZ)-induced diabetes.

\section{MATERIALS AND METHODS}

\section{Materials}

The MFE powder was provided by Kemai Biomedical Co. Ltd. (Changchun, China). We analyzed its composition using HPLC for moisture (6.81\%), total phenolics $(3.45 \%)$, total flavonoids $(2.24 \%)$, and total mogrosides $(87.5 \%)$ with the colorimetric method. A pelletized high-fat diet ( $45 \% \mathrm{kcal}$ fat) was purchased from Jiangsu Medicine Biomedical Co. Ltd. (Yangzhou, China). Streptozotocin was purchased from Sigma-Aldrich (St. Louis, MO). Milk and sucrose were purchased from Zhongjun supermarket (Harbin, China). The freezedried direct-to-vat inoculation starter culture (ABY-8, Chr. Hansen, Milwaukee, WI) was a blend of Streptococcus thermophilus and Lactobacillus delbrueckii ssp. bulgaricus, with Bifidobacterium BB-12 and Lactobacillus acidophilus LA-5 as starter adjuncts. Whey protein isolate (92\% protein, wt/wt) was purchased from Fonterra (Auckland, New Zealand) and inulin (93\%, wt/ wt) was purchased from Zhangye Biomedical Co. Ltd. (Zhangye, China). Low-methoxyl (DE 23) pectin was donated by Cpkelco (Lille Skensved, Denmark). Unless otherwise indicated, all other chemicals used in the study were of analytical grade.

\section{Preparation of the Synbiotic Yogurt}

Polymerized whey protein was prepared according to the method of Wang et al. (2012) with some modifications. First, whey protein isolate was dissolved in deionized water $(10 \%, \mathrm{wt} / \mathrm{vol})$ and kept at $4^{\circ} \mathrm{C}$ overnight. Then, the solution was adjusted to $\mathrm{pH} 7.0$ with $2 \mathrm{~mol} / \mathrm{L}$ $\mathrm{NaOH}$ and heated to $85^{\circ} \mathrm{C}$ for $30 \mathrm{~min}$ in a water bath to induce polymerization of whey protein. The treated protein solution was cooled to room temperature in an ice water bath.

The milk was heated to $60^{\circ} \mathrm{C}$, and $\mathrm{MFE}$ (low dose, $5 \mathrm{mg} / \mathrm{mL}$; medium dose, $10 \mathrm{mg} / \mathrm{mL}$; high dose, 30 $\mathrm{mg} / \mathrm{mL})$ or sucrose $(30 \mathrm{mg} / \mathrm{mL})$, as well as inulin $(10$ $\mathrm{mg} / \mathrm{mL})$ and pectin $(3 \mathrm{mg} / \mathrm{mL})$ were added slowly. The mixture was kept at $85^{\circ} \mathrm{C}$ for $10 \mathrm{~min}$ and then quickly cooled with ice water. When the mixture had cooled to $43^{\circ} \mathrm{C}$, it was inoculated with the inoculation starter culture ABY-8 $(0.3 \mathrm{mg} / \mathrm{mL})$ and polymerized whey protein $(4 \mathrm{mg} / \mathrm{mL})$. After stirring, the mixture was fermented at $43^{\circ} \mathrm{C}$ for $5 \mathrm{~h}$. Then, the yogurt was cooled and stored at $4^{\circ} \mathrm{C}$ for further use $(\mathrm{pH} 4.5)$. Thus, the final concentration of MFE in the synbiotic yogurt was approximately 5,10 , and $30 \mathrm{mg} / \mathrm{mL}$ in the low, medium, and high dose treatments, respectively. The final concentration of sucrose in the control yogurt was approximately $30 \mathrm{mg} / \mathrm{mL}$.

\section{Animal Models}

All experiments were conducted in accordance with the guidelines for animal experimentation established by the Laboratory Animal Care and Use Committee of Jiangnan University [SYXK (SU) 2016-0045; approval number JN. No20180915W0801120(194)].

Seventy Wistar rats (5 wk old, male, specific-pathogen-free grade) were purchased from Shanghai Slake Animal Center (Shanghai, China). All rats were housed at a constant temperature $\left(22^{\circ} \mathrm{C} \pm 2^{\circ} \mathrm{C}\right)$ and humidity $(55 \% \pm 5 \%)$ with a 12-h light:dark cycle (0800 to 2000 $\mathrm{h}$ and 2000 to $0800 \mathrm{~h}$ ). The rats were divided into 7 groups according to BW. The control group consisted of 10 rats that were freely given a normal diet and water for the first week to adapt to their new environment. On the first day of wk 2 , the rats were intraperitoneally injected with $50 \mathrm{mmol} / \mathrm{L}$ citrate buffer (pH 4.5). From wk 2 to 7 , they were given a normal diet and administered $30 \mathrm{mg} / \mathrm{mL}$ sucrose at a dose of $100 \mathrm{mg} /$ $\mathrm{kg}$ of BW. The diabetes control group, (SIDR), the control yogurt group (CY), the low-dose yogurt group (MY-L), the medium-dose yogurt group (MY-M), the high-dose yogurt group (MY-H), and the metformin 
group (Dix) also consisted of 10 rats each. Similar to the control group, the rats in these groups were allowed to adapt to the new environment in the first week, but from wk 2 to 7 , these 6 groups received a high-fat diet. On the first day of wk 2, these rats were intraperitoneally injected with STZ freshly dissolved in $50 \mathrm{mmol} / \mathrm{L}$ citrate buffer $(\mathrm{pH} 4.5)$ at a dose of $100 \mathrm{mg} / \mathrm{kg}$ of BW. From wk 2 to 7 , the SIDR group was treated with 30 $\mathrm{mg} / \mathrm{mL}$ sucrose solution once per day; the CY group received sucrose orally at a low dose of $30 \mathrm{mg} / \mathrm{mL}$ control yogurt; the MY-L group received MFE orally at a low dose of $5 \mathrm{mg} / \mathrm{mL}$ synbiotic yogurt; the MY-M group received MFE orally at a medium dose of $10 \mathrm{mg} / \mathrm{mL}$ synbiotic yogurt; and the MY-H received MFE orally at a high dose of $30 \mathrm{mg} / \mathrm{mL}$ synbiotic yogurt. The Dix group was treated with $300 \mathrm{mg} / \mathrm{kg}$ of BW of metformin. On d 7 after the STZ injection, rats with a blood glucose (BG) level greater than $10.0 \mathrm{mmol} / \mathrm{L}$ were categorized as having diabetes. Fasting blood glucose was measured with a One Touch Ultra blood glucose meter (Life Scan, Milpitas, NJ) after a 12-h fast once every 2 wk using blood collected from the tail vein. At the end of the experiment, blood samples were obtained from the orbital venous plexus after a 12-h fast. Serum was obtained by centrifugation of blood samples at 3,000 $\times$ $g$ for 15 min at $4^{\circ} \mathrm{C}$.

\section{Biochemical Analysis}

The levels of serum insulin were determined using a commercial ELISA kit (R\&D systems, Rochester, MN). We measured glycosylated hemoglobin (HbA1c) using a commercial kit (Nanjing Jiancheng Biotechnology Co. Ltd., Nanjing, China). The homeostasis model assessment insulin resistance (HOMA-IR) was calculated as HOMA-IR $=$ fasting insulin level $\times$ fasting blood glucose/22.5 (Tuepker, 2003).

\section{Measurement of Glucose Tolerance}

The oral glucose tolerance test (OGTT) was used to measure the glucose tolerance. After $12 \mathrm{~h}$ of fasting, rats were administered $2.5 \mathrm{~g} / \mathrm{kg}$ glucose by intragastric injection. Then, BG samples were collected from the tail vein at $0,30,60$, and $120 \mathrm{~min}$. Area under the curve (AUC) was calculated using the following formula (Chen et al., 2016):

$$
\begin{gathered}
\mathrm{AUC}=1 / 4 \times \mathrm{BG}(0 \text { min })+1 / 2 \times \mathrm{BG}(30 \mathrm{~min}) \\
+3 / 4 \times \mathrm{BG}(60 \text { min })+1 / 2 \times \mathrm{BG}(120 \text { min }) .
\end{gathered}
$$

\section{Measurement of Organ Coefficients}

After the rats were killed, liver, kidney, spleen, and thymus tissues were immediately removed and rinsed with ice-cold $0.85 \%$ saline solution. The capsules of tissues were removed carefully and the tissues were weighed promptly. Organ coefficients were defined as the weight of the tissue $(\mathrm{mg})$ divided by the weight of the rat (g; Chen et al., 2016).

\section{Histological Analysis of Pancreas}

Pancreas tissues were also immediately removed and rinsed with ice-cold saline solution $(0.85 \%)$. Tissues were fixed in $4 \%$ paraformaldehyde for $24 \mathrm{~h}$, followed by dehydration in gradient alcohol solution and transparency in xylol. The tissues were embedded in paraffin and cut into sections $5 \mu \mathrm{m}$ thick. The paraffin section was stained with a conventional hematoxylin-eosin (HE) staining method and examined using a Nikon Optical Light Microscope (Nikon Corporation, Tokyo, Japan; Chen et al., 2016).

\section{Immunohistochemistry Analysis}

We performed immunohistochemistry analysis of all pancreas samples. The paraffin-embedded pancreas samples were cut into $5-\mu \mathrm{m}$ sections. The sections were dewaxed, rehydrated, heated and then immunostained using a primary antibody of insulin (Cell Signaling Technology, Beverly, MA), followed by incubation with a peroxidase-conjugated rabbit antiguinea rat secondary antibody. Finally, color was revealed using 3,3'-diaminobenzidine hydrochloride.

\section{Fecal Analysis for Short-Chain Fatty Acids and Gut Microbiota}

Rat feces were collected $1 \mathrm{~d}$ before the end of the study period. We analyzed the feces for short-chain fatty acids (SCFA), including acetate, propionate, and butyric acid using GC-MS (QP-2010 Ultra system, Shimadzu Corporation, Kyoto, Japan). Fecal samples (200 $\mathrm{mg}$ ) were collected directly into sterile tubes from live rats, homogenized in $1 \mathrm{~mL}$ of sterile water, and then oscillated for $10 \mathrm{~min}$. The suspension was centrifuged at $18,800 \times g$ for $10 \mathrm{~min}$, and the supernatant was centrifuged again at $18,800 \times g$ for $15 \mathrm{~min}$. The supernatant was subjected to $0.45 \mu \mathrm{m}$ membrane filtration. The filtrate $(1 \mathrm{~mL})$ and formic acid $(0.1 \mathrm{~mL})$ were taken into a gas-phase flask for SCFA analysis (Qu et al., 2018). 
The gut microbiota in the fecal samples were determined according to a metagenomic method developed by Mao et al. (2015). Microbial genomic DNA was extracted from the fecal samples using a Fast DNA Spin Kit for Soil (catalog no. 6560-200; MP Biomedicals, Santa Ana, CA), and then the V4 region of the $16 \mathrm{~S}$ rRNA was amplified by PCR, quantified using a QuantiT PicoGreen dsDNA Assay Kit (catalog no. P7589; Life Technologies, Carlsbad, CA), and sequenced for $500+7$ cycles on an Illumina Miseq sequencer (Illumina Inc., San Diego, CA) using the MiSeq Reagent Kit (500 cycles-PE, catalog no. MS-102-2003; Illumina Inc.). We used the normalized and log-transformed abundance data for heat mapping with the heatmap package in R (https://www.R-project.org/).

\section{Statistical Analysis}

Data are presented as means \pm standard deviation of 10 rats in each group. All data were analyzed by SPSS 17.0 (IBM Corp., Armonk, NY). Differences among groups were assessed using a 1-way ANOVA followed by Duncan's multiple-range test. A value of $P<0.05$ was considered to be significantly different.

\section{RESULTS}

\section{Fasting BG Levels}

Mean fasting BGlevel for each group are shown in Table 1. We found no differences in fasting BG between groups for the first $28 \mathrm{~d}(P>0.05)$. By d 42 , the fasting $\mathrm{BG}$ of the SIDR group was statistically different from those of the other groups $(P<0.05)$. The fasting BG level of the SIDR group was significantly higher than that of the control group and the treatment groups after injection of STZ $(P<0.05)$. Compared with the SIDR group, the fasting BG of the CY, MY-L, MY$\mathrm{M}$, and MY-H groups decreased by 19.0, 39.9, 42.4, and $38.8 \%$, respectively, indicating that yogurt fortified with MFE had a more positive effect on the fasting BG than the control yogurt. Fasting BG levels in the Dix group were significantly lower than those in the SIDR group following STZ injection.

\section{Oral Glucose Tolerance}

The results for glucose tolerance in each group are shown in Figure 1. After glucose was administered, the mean BG level of each group increased; the control and Dix groups reached peak BG levels at $30 \mathrm{~min}$, and other groups reached the peak at $60 \mathrm{~min}$ and then decreased gradually. These results showed that type 2 diabetes induced by a high-fat diet and STZ injection postponed the BG peak time in the SIDR and the treatment groups. At 120 min, BG levels had returned to normal in the control and Dix groups, but remained high in the SIDR group and the treatment groups. However, compared with the SIDR group, BG levels in the different yogurt groups were closer to normal at $120 \mathrm{~min}$. Blood glucose levels in the MY-H group were lower than those in the CY group. The AUC of rats with diabetes were significantly higher than that of the control group $(P$ $<0.05$ ). Compared with the SIDR group, the synbiotic yogurt treatment groups showed enhanced glucose tolerance. At the end of the experiment, the glucose AUC for the MY-H group was also significantly lower than that of the SIDR group $(P<0.05)$.

Table 1. Effects on fasting blood glucose $(\mathrm{mmol} / \mathrm{L})$ after feeding rats a synbiotic yogurt fortified with monk fruit extract

\begin{tabular}{lcrrr}
\hline & \multicolumn{4}{c}{ Time after feeding (d) } \\
\cline { 2 - 5 } Group $^{1}$ & \multicolumn{1}{c}{0} & \multicolumn{1}{c}{28} & \multicolumn{1}{c}{42} \\
\hline Control & $4.16 \pm 0.31^{\mathrm{a}}$ & $5.14 \pm 0.33^{\mathrm{a}}$ & $4.69 \pm 0.29^{\mathrm{a}}$ & $5.32 \pm 0.58^{\mathrm{a}}$ \\
SIDR & $3.92 \pm 0.43^{\mathrm{a}}$ & $4.5 \pm 0.19^{\mathrm{a}}$ & $5 \pm 0.26^{\mathrm{a}}$ & $18.53 \pm 2.71^{\mathrm{e}}$ \\
CY & $4.29 \pm 0.31^{\mathrm{a}}$ & $4.77 \pm 0.54^{\mathrm{a}}$ & $4.62 \pm 0.4^{\mathrm{a}}$ & $15.01 \pm 0.95^{\mathrm{d}}$ \\
MY-L & $4.05 \pm 0.35^{\mathrm{a}}$ & $4.64 \pm 0.19^{\mathrm{a}}$ & $4.65 \pm 0.46^{\mathrm{a}}$ & $11.14 \pm 1.65^{\mathrm{c}}$ \\
MY-M & $3.95 \pm 0.27^{\mathrm{a}}$ & $4.82 \pm 0.35^{\mathrm{a}}$ & $4.77 \pm 0.28^{\mathrm{a}}$ & $10.67 \pm 2.33^{\mathrm{c}}$ \\
MY-H & $4.03 \pm 0.34^{\mathrm{a}}$ & $4.95 \pm 0.49^{\mathrm{a}}$ & $4.47 \pm 0.23^{\mathrm{a}}$ & $11.34 \pm 2.03^{\mathrm{c}}$ \\
Dix & $4.26 \pm 0.37^{\mathrm{a}}$ & $4.43 \pm 0.53^{\mathrm{a}}$ & $4.46 \pm 0.34^{\mathrm{a}}$ & $7.78 \pm 0.54^{\mathrm{b}}$ \\
\hline
\end{tabular}

${ }^{\mathrm{a} e \mathrm{e}}$ Different lowercase letters within a column denote significant differences between groups at $P<0.05$. ${ }^{1}$ Control = rats fed a normal diet and water, $30 \mathrm{mg} / \mathrm{mL}$ sucrose; SIDR = diabetes control group, $30 \mathrm{mg} / \mathrm{mL}$ sucrose; $\mathrm{CY}=$ control yogurt group, $30 \mathrm{mg} / \mathrm{mL}$ control yogurt; $\mathrm{MY}-\mathrm{L}=$ low-dose yogurt group, $5 \mathrm{mg} / \mathrm{mL}$ synbiotic yogurt; MY-M = medium-dose yogurt group, $10 \mathrm{mg} / \mathrm{mL}$ synbiotic yogurt; MY-H = high-dose yogurt group, $30 \mathrm{mg} / \mathrm{mL}$ synbiotic yogurt; Dix = metformin group, $300 \mathrm{mg} / \mathrm{kg}$ metformin. On the first day of wk 6 , the SIDR, CY, MY-L, MY-M, MY-H, and Dix group received streptozotocin freshly dissolved in $50 \mathrm{mmol} / \mathrm{L}$ citrate buffer $(\mathrm{pH} 4.5)$ at a dose of $100 \mathrm{mg} / \mathrm{kg}$ of BW. 
Effects of the Synbiotic Yogurt on Insulin, HOMA-IR, and $\mathrm{HbA1c}$ Levels

Insulin, HOMA-IR, and HbA1c levels after $42 \mathrm{~d}$ of each group are shown in Figure 2 and were significantly higher in the SIDR group than the control group $(P$ $<0.05)$. Compared with the SIDR group, insulin, HOMA-IR, and HbA1c levels were lower for the treatment groups. For the CY, MY-L, MY-M, MY-H, and Dix groups, serum insulin levels were reduced by 14.8 ,
17.6, 20.6, 26.7, and 40.13\%, respectively, and HbA1c levels were reduced by $6.42,11.6,12.9,18.3$, and $21.1 \%$, respectively.

\section{Effects of the Synbiotic Yogurt on Organ Coefficients}

The organ coefficients of rats in each group after 42 $\mathrm{d}$ are shown in Table 2 . We found significant differences in the coefficient values of liver and kidney between the
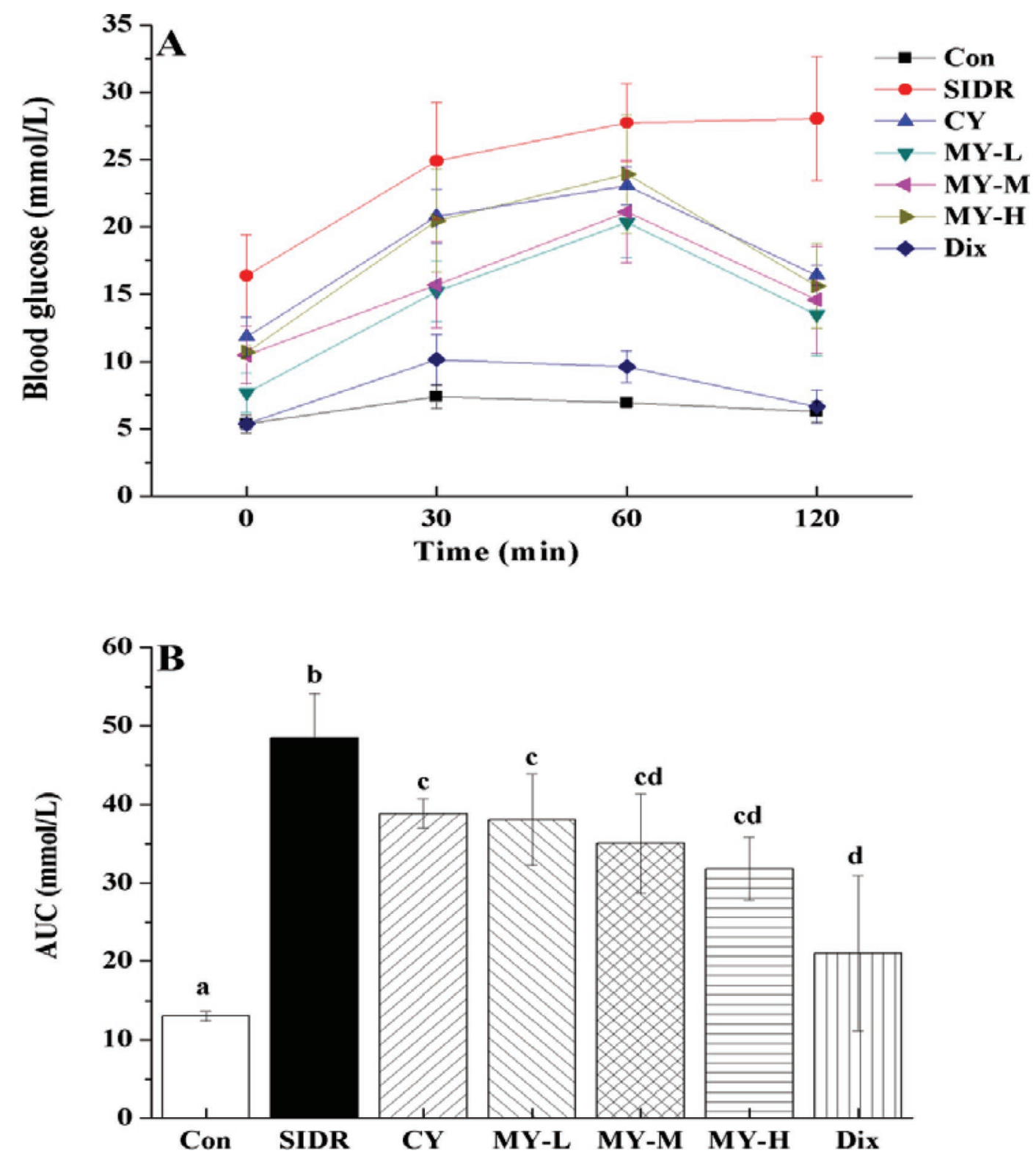

Figure 1. Effects on (A) oral glucose tolerance test, and (B) area under the curve (AUC) for blood glucose after feeding rats a synbiotic yogurt fortified with monk fruit extract. Control = rats fed a normal diet and water, $30 \mathrm{mg} / \mathrm{mL}$ sucrose; SIDR = diabetes control group, 30 $\mathrm{mg} / \mathrm{mL}$ sucrose; $\mathrm{CY}=$ control yogurt group, $30 \mathrm{mg} / \mathrm{mL}$ control yogurt; $\mathrm{MY}-\mathrm{L}=$ low-dose yogurt group, $5 \mathrm{mg} / \mathrm{mL}$ synbiotic yogurt; $\mathrm{MY}-\mathrm{M}=$ medium-dose yogurt group, $10 \mathrm{mg} / \mathrm{mL}$ synbiotic yogurt; $\mathrm{MY}-\mathrm{H}=$ high-dose yogurt group, $30 \mathrm{mg} / \mathrm{mL}$ synbiotic yogurt; Dix = metformin group, $300 \mathrm{mg} / \mathrm{kg}$ metformin. On the first day of wk 6, the SIDR, CY, MY-L, MY-M, MY-H, and Dix group received streptozotocin freshly dissolved in $50 \mathrm{mmol} / \mathrm{L}$ citrate buffer $(\mathrm{pH} 4.5)$ at a dose of $100 \mathrm{mg} / \mathrm{kg}$ of BW. Different lowercase letters (a-d) denote significance differences between groups at $P<0.05$. Values are mean $\pm \mathrm{SD}$ from 10 rats per group $(\mathrm{n}=10)$. 

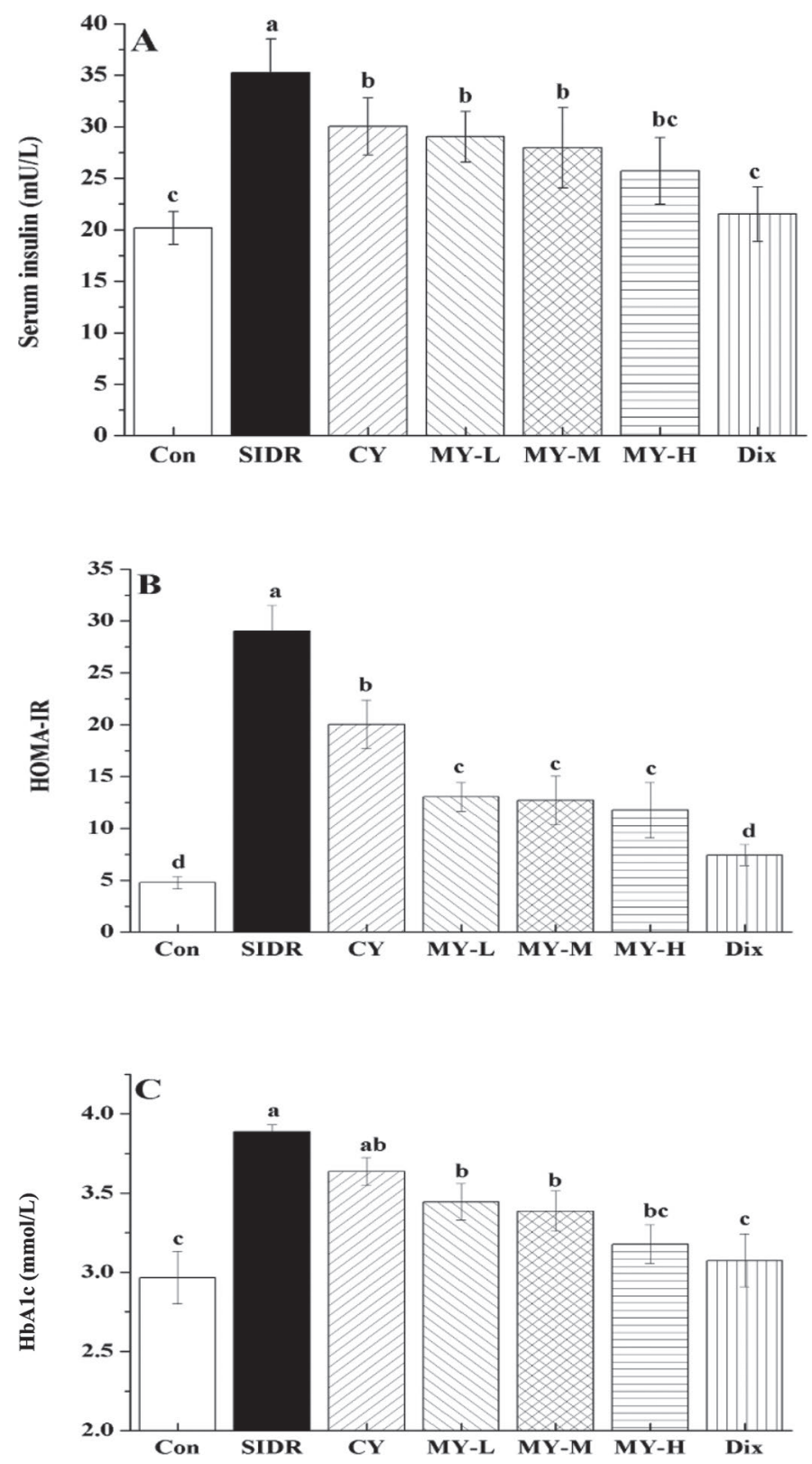

Figure 2. Effects on serum insulin, homeostasis model assessment of insulin resistance (HOMA-IR), and glycosylated hemoglobin (HbA1c) levels of feeding rats a synbiotic yogurt fortified with monk fruit extract. Control = rats fed a normal diet and water, $30 \mathrm{mg} / \mathrm{mL}$ sucrose; SIDR = diabetes control group, $30 \mathrm{mg} / \mathrm{mL}$ sucrose; $\mathrm{CY}=$ control yogurt group, $30 \mathrm{mg} / \mathrm{mL}$ control yogurt; MY-L = low-dose yogurt group, $5 \mathrm{mg} / \mathrm{mL}$ synbiotic yogurt; $\mathrm{MY}-\mathrm{M}$ = medium-dose yogurt group, $10 \mathrm{mg} / \mathrm{mL}$ synbiotic yogurt; $\mathrm{MY}-\mathrm{H}$ = high-dose yogurt group, $30 \mathrm{mg} / \mathrm{mL}$ synbiotic yogurt; Dix = metformin group, $300 \mathrm{mg} / \mathrm{kg}$ metformin. On the first day of wk 6, the SIDR, CY, MY-L, MY-M, MY-H, and Dix group received streptozotocin freshly dissolved in $50 \mathrm{mmol} / \mathrm{L}$ citrate buffer (pH 4.5) at a dose of $100 \mathrm{mg} / \mathrm{kg}$ of BW. Different lowercase letters (a-d) denote significance differences between groups at $P$ $<0.05$. Values are mean $\pm \mathrm{SD}$ from 10 rats per group $(\mathrm{n}=10)$.
SIDR and control groups $(P<0.05)$, but no effect on the thymus or spleen $(P>0.05)$. The coefficients of liver and kidney were significantly lower for the rats of MY-H and Dix groups compared with rats in the SIDR group $(P<0.05)$, but we found no effect on the thymus and spleen $(P>0.05)$. Coefficient values of the liver and kidney for the MY-H group were lower than those for the CY group $(P<0.05)$. The effect on the liver coefficient in the MY-H group exceeded that of the MY-L or MY-M groups, resulting in a dose-dependent effect, meaning that the synbiotic yogurt alleviated liver and kidney damage caused by STZ and a high-fat diet.

\section{Tissue Changes in the Pancreas}

The HE-stained sections of pancreas for each group are shown in Figure 3. We found significant differences in the overall pattern and number of islets of Langerhans in each group. The islets of Langerhans were round and large with clear boundaries and full central particles (Figure 3A, G) in the control and Dix groups. In the SIDR group, the islets presented atrophy inordinately, boundaries unclear, and the number of central particles was reduced (Figure 3B). In the yogurt treatment groups, the area of islets was small, but their shape was inerratic and the number of central particles was increased compared with the SIDR group, indicating that the synbiotic yogurt improved pancreatic tissue damaged by STZ (Figure 3C-F). The MY-H group showed better effect on the islets than the CY group (Figure 3C, F).

\section{Immunohistochemistry of the Pancreas}

Pancreas histopathological examination (Figure 4AG) showed no abnormality of the pancreas architecture and morphology in the control rats. Immunohistochemistry stain of islets demonstrated that the expression of insulin is brown-yellow granules, which represented $\beta$ cytoplasm. The pancreatic islets of the control group were intact, and insulin-positive granules were stained brown-yellow, located in the cytoplasm, and clearly demarcated (Figure 4A). In the SIDR group, the number of insulin-positive particles decreased, and the staining was relatively shallow. The proportion of positive staining in the islet area decreased, and the boundary was not clear (Figure 4B). Compared with the SIDR group, positive granules in the islets of the yogurt-treated and Dix groups increased and the islet area increased (Figure 4C-G). Image analysis revealed insulin-stained positive cells in the area, and the integral absorbance of SIDR group was significantly lower than that of the control group $(P<0.05)$. The MY-M, MY-H, and Dix 


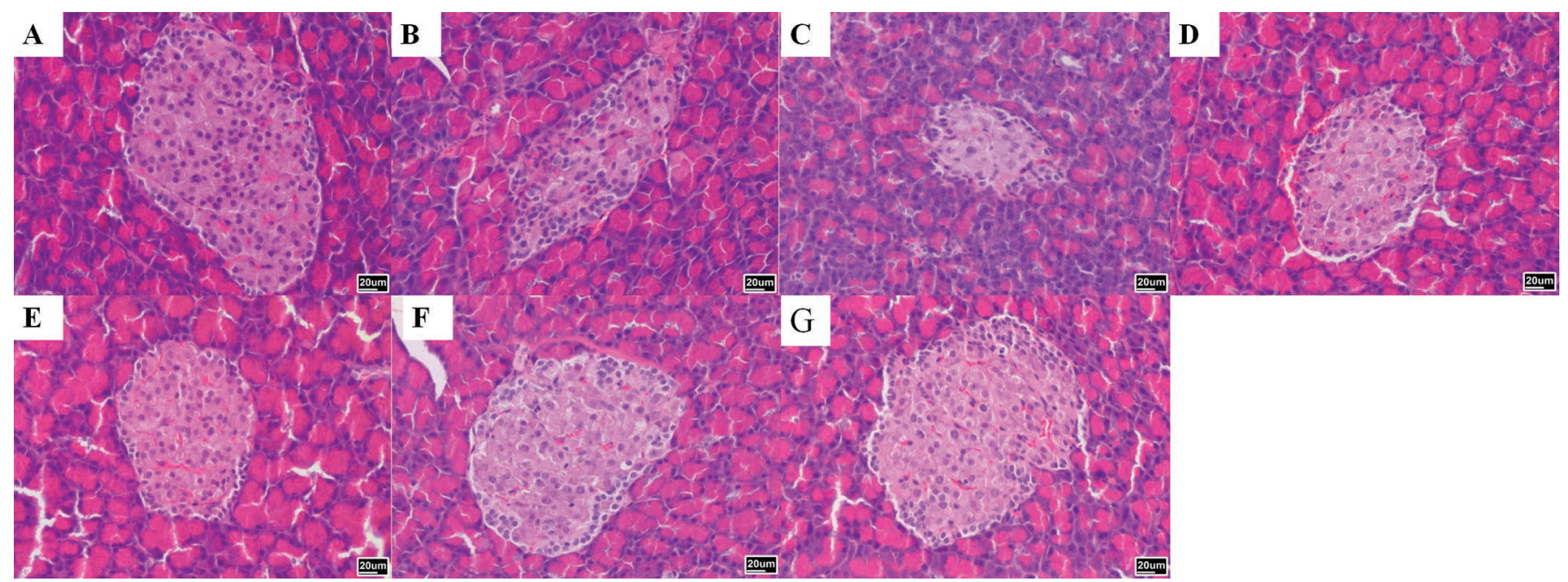

Figure 3. Effects on pancreas staining (hematoxylin and eosin) of feeding rats a synbiotic yogurt fortified with monk fruit extract. (A) Control, (B) SIDR, (C) CY, (D) MY-L, (E) MY-M, (F) MY-H, (G) Dix (magnified diameter $20 \mu \mathrm{m}$ ). Control = rats fed a normal diet and water, $30 \mathrm{mg} / \mathrm{mL}$ sucrose; SIDR = diabetes control group, $30 \mathrm{mg} / \mathrm{mL}$ sucrose; $\mathrm{CY}=$ control yogurt group, $30 \mathrm{mg} / \mathrm{mL}$ control yogurt; $\mathrm{MY}-\mathrm{L}=\mathrm{low}$-dose yogurt group, $5 \mathrm{mg} / \mathrm{mL}$ synbiotic yogurt; MY-M = medium-dose yogurt group, $10 \mathrm{mg} / \mathrm{mL}$ synbiotic yogurt; MY-H = high-dose yogurt group, $30 \mathrm{mg} / \mathrm{mL}$ synbiotic yogurt; Dix = metformin group, $300 \mathrm{mg} / \mathrm{kg}$ metformin. On the first day of wk 6, the SIDR, CY, MY-L, MY-M, MY-H, and Dix group received streptozotocin freshly dissolved in $50 \mathrm{mmol} / \mathrm{L}$ citrate buffer $(\mathrm{pH} 4.5)$ at a dose of $100 \mathrm{mg} / \mathrm{kg}$ of BW.

groups all showed repaired pancreatic islets to different degrees $(P<0.05)$ (Figure $4 \mathrm{H})$, but the MY-H group showed a higher effect than the other groups.

\section{Short-Chain Fatty Acid Levels in Feces}

As shown in Figure 5, the rats with diabetes showed reduced concentrations of acetic acid, propionic acid, and butyric acid compared with the control rats. Supplementation in the MY-L, MY-M, MY-H, and Dix groups resulted in significantly increased SCFA levels $(P<0.05)$. For the CY, MY-L, MY-M, and MY-H groups, acetic acid levels increased by 16.8, 18.1, 19.8, and $40.0 \%$; propionic acid increased by $3.67,0,12.6$, and $39.3 \%$; and butyric acid increased by $15.7,21.3$, 31.1 , and $59.7 \%$, respectively.

\section{Gut Microbiota}

At the phylum level, the total fecal microbial system of all of the rats comprised Firmicutes, Bacteroidetes, Actinobacteria, Cyanobacteria, Deferribacteres, Proteobacteria, TM7, Tenericutes, and Verrucomicrobia (Figure 6). The abundance of Firmicutes, Bacteroidetes, and Verrucomicrobia showed significant differences between the control and SIDR groups $(P<0.05)$. Moreover, the

Table 2. Effects on organ coefficients (mg/g of BW) of feeding rats a synbiotic yogurt fortified with monk fruit extract

\begin{tabular}{|c|c|c|c|c|}
\hline \multirow[b]{2}{*}{ Group $^{1}$} & \multicolumn{4}{|c|}{ Organ } \\
\hline & Liver & Thymus & Spleen & Kidney \\
\hline$\overline{\text { Control }}$ & $37.78 \pm 5.7^{\mathrm{a}}$ & $1.19 \pm 0.31^{\mathrm{a}}$ & $1.89 \pm 0.23^{\mathrm{a}}$ & $6.11 \pm 0.58^{\mathrm{a}}$ \\
\hline SIDR & $57.65 \pm 3.93^{\mathrm{c}}$ & $1.24 \pm 0.25^{\mathrm{a}}$ & $1.97 \pm 0.17^{\mathrm{a}}$ & $8.11 \pm 0.48^{\mathrm{c}}$ \\
\hline $\mathrm{CY}$ & $62.46 \pm 3.10^{\mathrm{d}}$ & $1.13 \pm 0.34^{\mathrm{a}}$ & $2.02 \pm 0.35^{\mathrm{a}}$ & $8.11 \pm 0.98^{\mathrm{c}}$ \\
\hline MY-L & $55.28 \pm 1.42^{\mathrm{c}}$ & $1.20 \pm 0.2^{\mathrm{a}}$ & $2.06 \pm 0.24^{\mathrm{a}}$ & $7.21 \pm 0.63^{\mathrm{b}}$ \\
\hline MY-M & $53.89 \pm 4.39^{\mathrm{bc}}$ & $1.19 \pm 0.3^{\mathrm{a}}$ & $1.90 \pm 0.4^{\mathrm{a}}$ & $7.18 \pm 0.42^{\mathrm{b}}$ \\
\hline MY-H & $50.52 \pm 4.83^{\mathrm{b}}$ & $0.94 \pm 0.29^{\mathrm{a}}$ & $1.80 \pm 0.3^{\mathrm{a}}$ & $7.16 \pm 0.37^{\mathrm{b}}$ \\
\hline Dix & $49.83 \pm 5.09^{\mathrm{b}}$ & $1.26 \pm 0.26^{\mathrm{a}}$ & $2.15 \pm 0.18^{\mathrm{a}}$ & $7.11 \pm 0.35^{\mathrm{b}}$ \\
\hline
\end{tabular}

$\overline{\mathrm{a}-\mathrm{d}}$ Different lowercase letters within a column denote significant differences between groups at $P<0.05$.

${ }^{1}$ Control $=$ rats fed a normal diet and water, $30 \mathrm{mg} / \mathrm{mL}$ sucrose; SIDR = diabetes control group, $30 \mathrm{mg} / \mathrm{mL}$ sucrose; $\mathrm{CY}=$ control yogurt group, $30 \mathrm{mg} / \mathrm{mL}$ control yogurt; MY-L = low-dose yogurt group, $5 \mathrm{mg} / \mathrm{mL}$ synbiotic yogurt; MY-M = medium-dose yogurt group, $10 \mathrm{mg} / \mathrm{mL}$ synbiotic yogurt; MY-H = high-dose yogurt group, $30 \mathrm{mg} / \mathrm{mL}$ synbiotic yogurt; Dix = metformin group, $300 \mathrm{mg} / \mathrm{kg}$ metformin. On the first day of wk 6 , the SIDR, CY, MY-L, MY-M, MY-H, and Dix group received streptozotocin freshly dissolved in $50 \mathrm{mmol} / \mathrm{L}$ citrate buffer $(\mathrm{pH} 4.5)$ at a dose of $100 \mathrm{mg} / \mathrm{kg}$ of BW. 

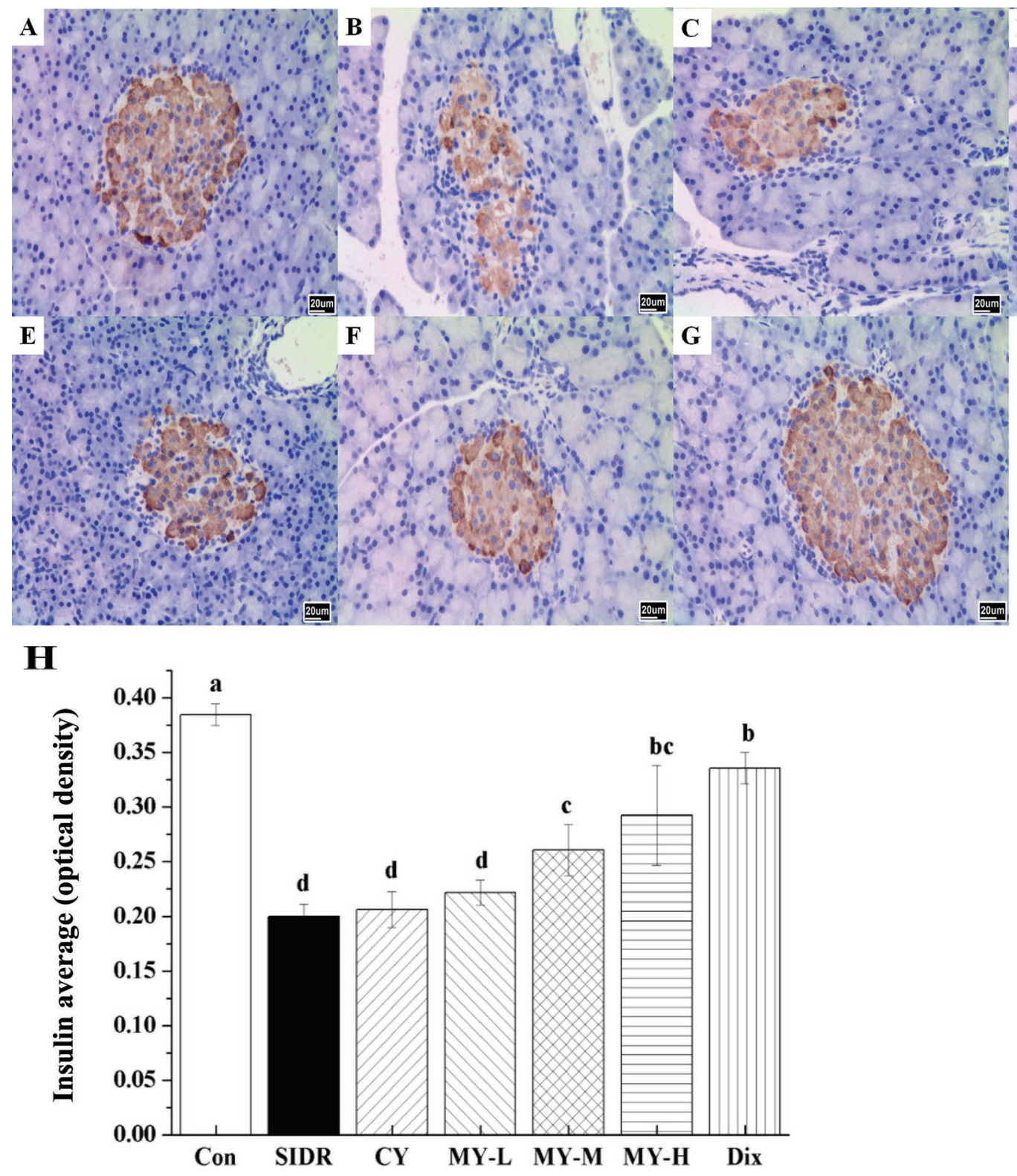

Figure 4. Effects on pancreas immunohistochemistry of feeding rats a synbiotic yogurt fortified with monk fruit extract. (A) Control, (B) SIDR, (C) CY, (D) MY-L, (E) MY-M, (F) MY-H, (G) Dix, (H) insulin average optical density (magnified diameter $20 \mu \mathrm{m}$ ). Control = rats fed a normal diet and water, $30 \mathrm{mg} / \mathrm{mL}$ sucrose; SIDR = diabetes control group, $30 \mathrm{mg} / \mathrm{mL}$ sucrose; CY = control yogurt group, $30 \mathrm{mg} / \mathrm{mL}$ control yogurt; MY-L = low-dose yogurt group, $5 \mathrm{mg} / \mathrm{mL}$ synbiotic yogurt; $\mathrm{MY}-\mathrm{M}=$ medium-dose yogurt group, $10 \mathrm{mg} / \mathrm{mL}$ synbiotic yogurt; $\mathrm{MY}$-H = high-dose yogurt group, $30 \mathrm{mg} / \mathrm{mL}$ synbiotic yogurt; Dix = metformin group, $300 \mathrm{mg} / \mathrm{kg}$ metformin. On the first day of wk 6, the SIDR, CY, MY-L, MY-M, MY-H, and Dix group received streptozotocin freshly dissolved in $50 \mathrm{mmol} / \mathrm{L}$ citrate buffer (pH 4.5$)$ at a dose of $100 \mathrm{mg} / \mathrm{kg}$ of BW. Different lowercase letters $(\mathrm{a}-\mathrm{d})$ denote significance differences between groups at $P<0.05$. Values are mean $\pm \mathrm{SD}$.

levels of those phyla, which were the 3 most abundant in the study, were altered after yogurt treatment $(P<$ $0.05)$. We selected 80 phylotypes as key variables for separating the gut microbiota under different treatment conditions at the genus level. The genera Lactobacillus, Akkermansia, and Bifidobacterium were markedly more abundant in the yogurt groups than in the SIDR group $(P<0.05)$. The MY-H group showed a more obvious effect on the genera Akkermansia and Bifidobacterium than the CY group $(P<0.05)$.

\section{DISCUSSION}

Excessive calorie intake has been identified as one of the primary reasons for increased risk of diabetes mellitus and obesity (Howard and Wylie-Rosett, 2002; 
Murphy and Johnson, 2003). This has driven the demands for effective sugar reduction strategies, such as replacement with low- or no-calorie alternative sweeteners. Alternative sweeteners can be synthetic or natural,
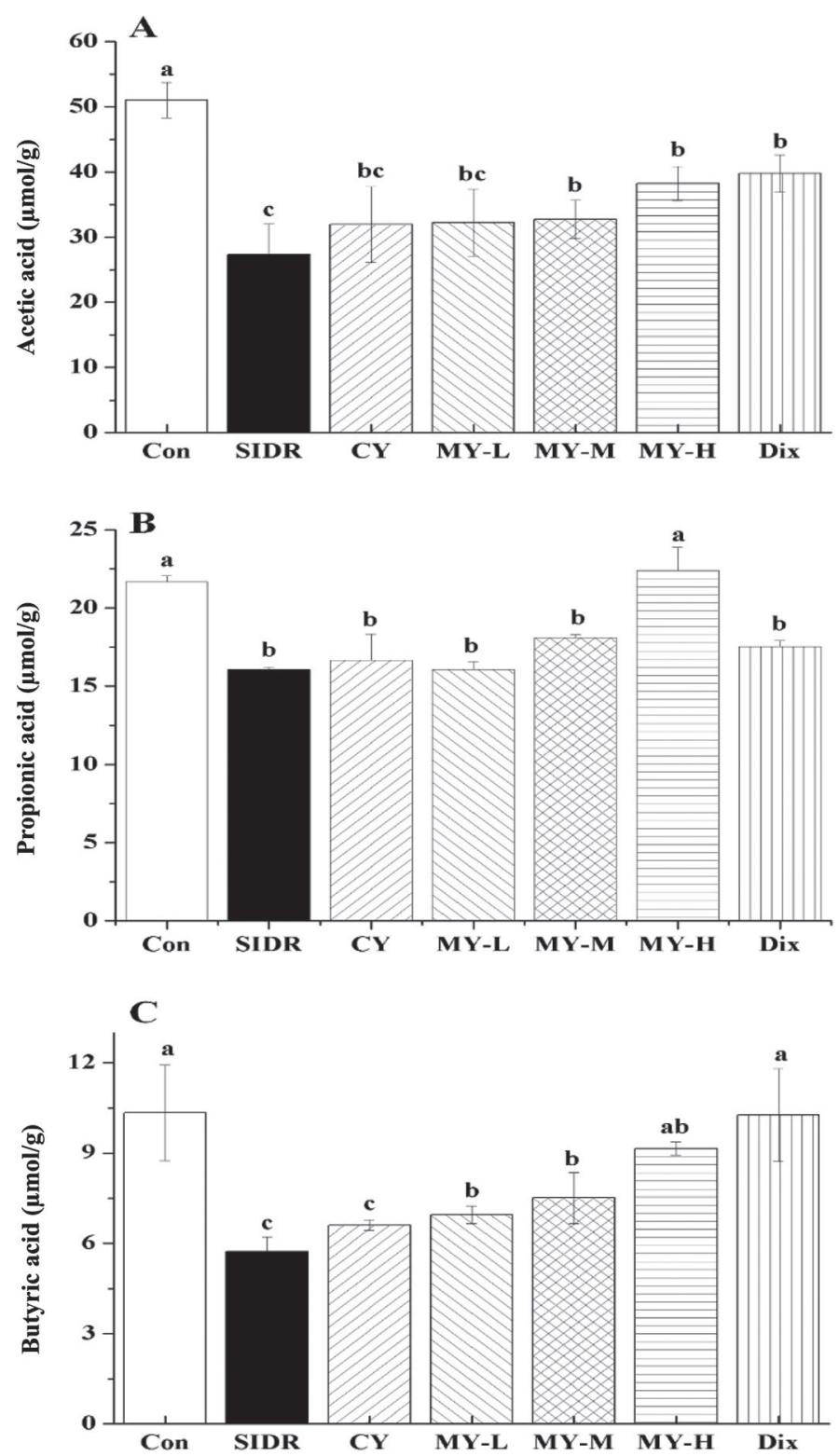

Figure 5. Effects on short-chain fatty acid levels of feeding rats a synbiotic yogurt fortified with monk fruit extract. (A) Acetic acid, (B) propionic acid, (C) butyric acid. Control = rats fed a normal diet and water, $30 \mathrm{mg} / \mathrm{mL}$ sucrose; SIDR = diabetes control group, $30 \mathrm{mg}$ / $\mathrm{mL}$ sucrose; $\mathrm{CY}=$ control yogurt group, $30 \mathrm{mg} / \mathrm{mL}$ control yogurt; MY-L = low-dose yogurt group, $5 \mathrm{mg} / \mathrm{mL}$ synbiotic yogurt; MY-M = medium-dose yogurt group, $10 \mathrm{mg} / \mathrm{mL}$ synbiotic yogurt; $\mathrm{MY}-\mathrm{H}=$ high-dose yogurt group, $30 \mathrm{mg} / \mathrm{mL}$ synbiotic yogurt; Dix = metformin group, $300 \mathrm{mg} / \mathrm{kg}$ metformin. On the first day of wk 6, the SIDR, CY MY-L, MY-M, MY-H, and Dix group received streptozotocin freshly dissolved in $50 \mathrm{mmol} / \mathrm{L}$ citrate buffer $(\mathrm{pH} 4.5)$ at a dose of $100 \mathrm{mg} / \mathrm{kg}$ of BW. Different lowercase letters $(\mathrm{a}-\mathrm{c})$ denote significance differences between groups at $P<0.05$. Values are mean $\pm \mathrm{SD}$. depending on their sources, or bulk or intense, depending on their sweetness potency (Kinghorn et al., 1998). Synthetic sweeteners such as saccharin, aspartame, acesulfame-K, and sucralose are widely used in the food industry. Given the negative consumer attitudes toward synthetic sweeteners, the food industry has been seeking natural alternative sweeteners (Moure et al., 2006).

Monk fruit extract consists of a group of triterpenoid glycosides. They are regarded as the main active ingredients for the sweet taste, and responsible for the main biological functions of monk fruit. Currently, MFE is used mainly for its antitussive, expectorant, antidiabetic, or sweet properties in Chinese herbal products and dietary supplements (Li et al., 2014). Oral administration of mogroside $\mathrm{V}$ in the treatment of STZ-induced diabetes mellitus mice has been studied (Qi et al., 2008; Liu et al., 2019). Mogroside V was used to prevent and treat diabetes mellitus, but the effect of foods fortified with MFE on type 2 diabetes has not been reported. In this study, we evaluated whether synbiotic yogurt fortified with MFE could improve hyperglycemia and have antidiabetic effects. Some reports have indicated the antidiabetic effects of pure mogroside in mice and rats (Chen et al., 2006; Qi et al., 2008; Liu et al., 2019). The antidiabetic effect of synbiotic yogurt fortified with MFE may be mainly due to mogrosides, but does not exclude the synergistic effect of the prebiotics and probiotics in yogurt. We set up a control yogurt group, for which the sweetener was sucrose. We administered the yogurt orally to rats, instead of intraperitoneal injection or other ingestion methods, making administration convenient and easy to implement. We formulated the synbiotic yogurt using MFE as sweetener to replace sucrose. Monk fruit extract has been recognized as a new type of supplement for functional food development. Therefore, synbiotic yogurt fortified with MFE may be a good choice for people with type 2 diabetes.

Long-term hyperglycemia can lead to tissue damage and organ pathological change, which in turn can cause the complications of diabetes. Strict glycemic control can reduce complications such as microvascular and cardiovascular disease (Nathan and DCCT/EDIC Research Group, 2014). Monk fruit extract and functional ingredients such as mogrosides and polysaccharides have been shown to have hypoglycemic effects on fasting and postprandial BG in diabetes models (Lin et al., 2007; Suzuki et al., 2007; Liu et al., 2019). Oral administration of synbiotic yogurt to rats for $42 \mathrm{~d}$ reduced fasting BG in SIDR rats. The CY group showed a little effect on reduced fasting BG. However, the difference between the SIDR group and groups that consumed yogurt rich in MFE was statistically significant $(P<$ 0.05 ), indicating that the yogurt had antidiabetic effects in the MY-L, MY-M, and MY-H groups after 6 
A

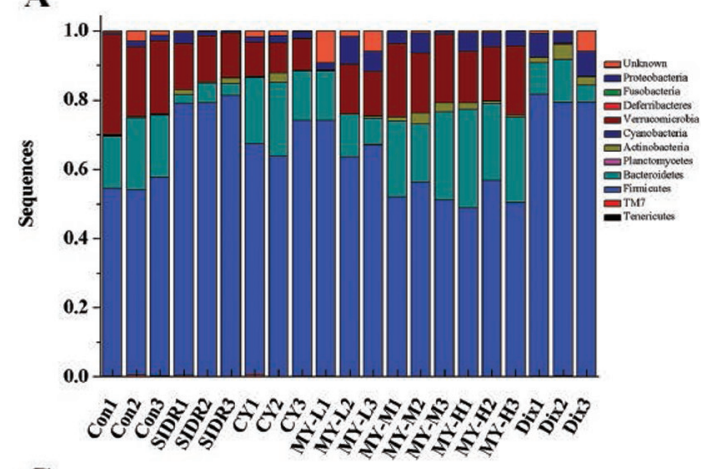

C

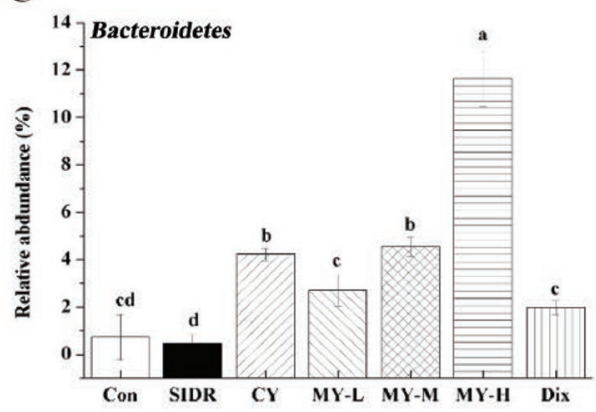

$\mathbf{E}$

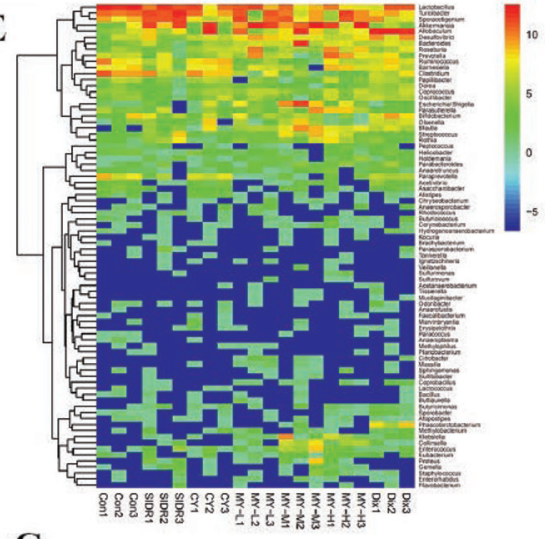

G

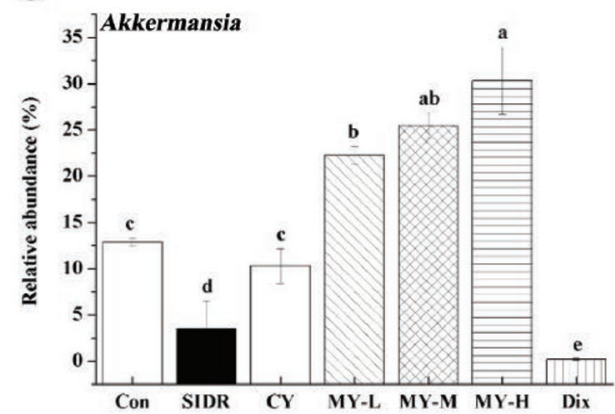

B

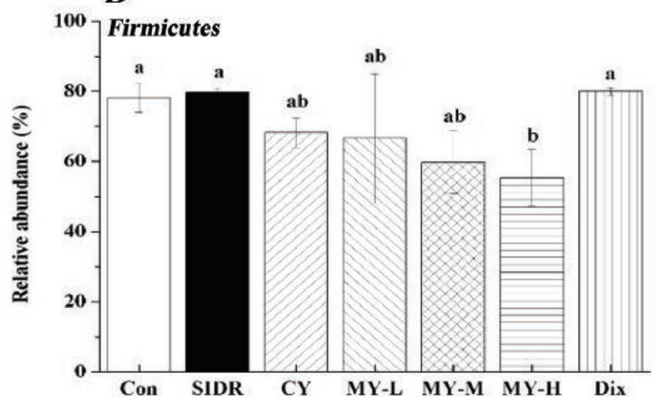

D

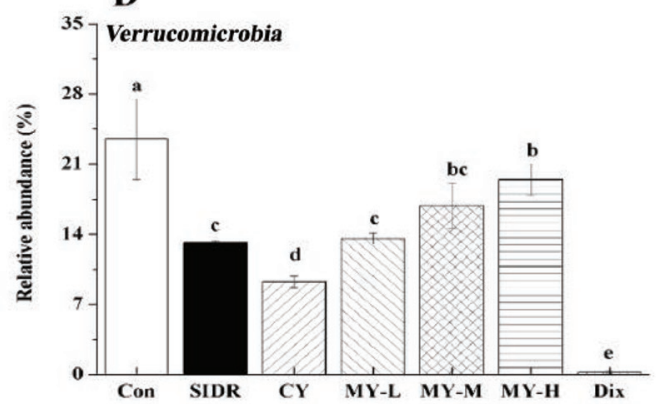

F

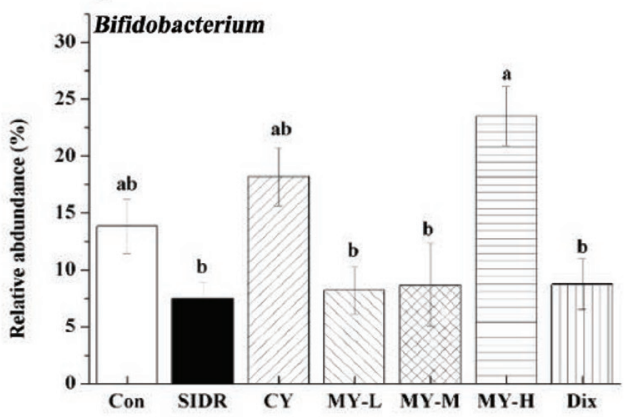

$\mathbf{H}$

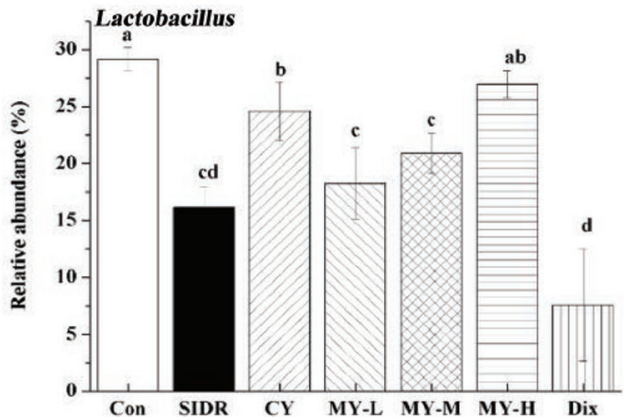

Figure 6. Effects on gut microbiota of feeding rats a synbiotic yogurt fortified with monk fruit extract. Relative abundance of (A) 7 groups at the phyla level; (B) relative abundance of Firmicutes in the 7 groups; (C) relative abundance of Bacteroidetes in the 7 groups; (D) relative abundance of Verrucomicrobia in the 7 groups; (E) heatmap of 81 most predictive phylotypes; (F) relative abundance of Bifidobacterium in the 7 groups; $(\mathrm{G})$ relative abundance of Akkermansia in the 7 groups; $(\mathrm{H})$ relative abundance of Lactobacillus in the 7 groups. Control $=$ rats fed a normal diet and water, $30 \mathrm{mg} / \mathrm{mL}$ sucrose; SIDR = diabetes control group, $30 \mathrm{mg} / \mathrm{mL}$ sucrose; CY = control yogurt group, $30 \mathrm{mg} / \mathrm{mL}$ control yogurt; MY-L = low-dose yogurt group, $5 \mathrm{mg} / \mathrm{mL}$ synbiotic yogurt; MY-M = medium-dose yogurt group, $10 \mathrm{mg} / \mathrm{mL}$ synbiotic yogurt; $\mathrm{MY}$-H = high-dose yogurt group, $30 \mathrm{mg} / \mathrm{mL}$ synbiotic yogurt; Dix = metformin group, $300 \mathrm{mg} / \mathrm{kg}$ metformin. On the first day of wk 6, the SIDR, CY, MY-L, MY-M, MY-H, and Dix group received streptozotocin freshly dissolved in $50 \mathrm{mmol} / \mathrm{L}$ citrate buffer ( $\mathrm{pH} 4.5)$ at a dose of $100 \mathrm{mg} / \mathrm{kg}$ of BW. Different lowercase letters (a-e) denote significance differences between groups at $P<0.05$. Values are mean \pm SD. 
wk of intervention. The synbiotic yogurt using MFE as a sweetener to replace sucrose had a positive effect on type 2 diabetes.

The oral glucose tolerance test has been used widely to diagnose diabetes by detecting the activity of islet cells and the body's ability to regulate BG levels (Tura et al., 2006). The AUC values in the SIDR group were higher than that of the control group, indicating that rats with diabetes exhibited impaired glucose tolerance. Feeding rats with low, medium, and high doses of MFE significantly reduced AUC values $(P<0.05)$, compared with the SIDR group. However, the CY group showed little effect in terms of reduced AUC value. These findings demonstrated that the synbiotic yogurt could improve glucose tolerance. Liu et al. (2019) also found that mogrosides prevented glucose intolerance induced by a high-fat diet and STZ in mice.

Several studies have confirmed that insulin resistance is a risk factor for the occurrence and development of chronic diseases such as type 2 diabetes, dyslipidemia, cardiovascular disease, nonalcoholic fatty liver disease, and even Alzheimer disease (Bender et al., 2013; Esser et al., 2014; Kim and Feldman, 2015). Liu et al. (2019) reported that high doses of mogroside-rich extract could reduce insulin resistance, enhance insulin sensitivity, and improve glucose and insulin tolerance. In this study, feeding synbiotic yogurt containing MFE significantly reduced serum insulin, HOMA-IR, and HbA1c levels compared with the SIDR group ( $P$ $<0.05$ ). The CY group showed low effects on serum insulin, HOMA-IR, and HbA1c levels. Oral administration of synbiotic yogurt fortified with MFE may reduce insulin resistance by reducing insulin secretion and relieving the symptoms of diabetes.

The liver and kidney of the SIDR group were hypertrophic, but in the treatment rats, liver and kidney weights were reduced. These data indicate that consumption of synbiotic yogurt could reduce damage to the liver and kidney caused by STZ and a high-fat diet. The CY group, fed yogurt sweetened with sucrose, showed little effect in terms of reducing damage to the liver and kidneys.

The islet of Langerhans secrete insulin and glucagon to stabilize BG levels and regulate glucose metabolism. In addition to impaired islet $\beta$ cells, inappropriate fasting glucagon secretion attributed to islet $\alpha$ cells is another important factor contributing to diabetes (Unger et al., 1970; Unger, 1985; Ali and Drucker, 2009). In rats receiving a high-fat diet and injected with STZ, pancreatic islet $\beta$ cells are damaged to mimic type 2 diabetes in an animal model. In the current study, the synbiotic yogurt fortified with MFE displayed good repair and recovery effects for islet $\beta$ cells, as seen from the HE staining results and insulin immunohistochem- istry assays. Several reports have discussed protecting the islets of Langerhans from destruction (Zhang et al., 2014; Bordalo Tonucci et al., 2017), but no detailed mechanisms for the effects of synbiotic yogurt on islet cells has been reported to date. Still, the results of decreasing insulin resistance with synbiotic yogurt indirectly add to our mechanistic understanding of $\beta$ cell protection by reducing the stimulation of islet $\beta$ cells. The effect of synbiotic yogurt on islet $\beta$ and $\alpha$ cells is a new finding, and the specific mechanism requires further investigation.

A recent study in people with obesity or diabetes indicated that specific microbiota composition may be associated with impaired glucose control (Karlsson et al., 2013; Zhao et al., 2018). The composition of the gut microbiota has been shown to contribute to the development of metabolic disorders by affecting the physiology and metabolism of the host (Shin et al., 2014). In the present study, at the phylum level, yogurt fortified with MFE increased the abundance of Bacteroidetes and Verrucomicrobia while decreasing the abundance of Firmicutes. In addition, the abundance of Verrucomicrobia was strongly increased by the oral administration of synbiotic yogurt fortified with MFE, compared with the group that received control yogurt. These phylum-level changes confirmed previous observations (De Vadder et al., 2014). Studies have reported that the relative abundance of Akkermansia, Lactobacillus, and Bifidobacterium, along with the metformin-mediated alleviation of type 2 diabetes and obesity, were enhanced in rats treated with yogurt (Zhang et al., 2015; Shin et al., 2014). Our results also showed that synbiotic yogurt treatments increased levels of Akkermansia, Lactobacillus, and Bifidobacterium. The relative abundance of Akkermansia spp., a mucin degrading bacteria with the potential to promote host immune system development and gut health, is generally increased in metformintreated obese mice or rats on a high-fat diet (Shin et al., 2014; Zhang et al., 2015). In the current study, we found obvious changes in microbial diversity or Akkermansia abundance in rats receiving synbiotic yogurt treatment. Possible reasons for this may be associated with the synbiotic yogurt fortified with MFE.

The fermentative activity of the gut microbiota degrades nondigestible polysaccharides or fiber into SCFA, mainly acetic acid, propionic acid, and butyric acid (Louis et al., 2007). Many physiological effects of the intestinal microbiota are caused by their metabolites. Short-chain fatty acids, the most important microbiota-derived metabolites, have been reported to improve type 2 diabetes through multiple mechanisms, such as regulation of BG levels and insulin resistance, as well as anti-inflammatory effects (Morrison and Preston, 2016; Jia et al., 2017; Qu et al., 2018). The consumption of 
yogurt led to an increase in SCFA levels. Butyric acid has been shown to prevent and treat diet-induced insulin resistance in rats (Gao et al., 2009). In the current study, oral administration of synbiotic yogurt fortified with MFE to rats increased SCFA levels compared with the CY group.

\section{CONCLUSIONS}

Our results indicated that the synbiotic yogurt fortified with MFE had a positive antidiabetic effect in rats with type 2 diabetes induced by a high-fat diet and STZ. The potential mechanism of this effect could be related to reduced insulin resistance, improved glucose control, protection of $\beta$-cell function, and improved intestinal microbiota. These results indicated that synbiotic yogurt fortified with MFE could be a good functional food for consumers with type 2 diabetes.

\section{ACKNOWLEDGMENTS}

The financial support for this project was provided by a special fund from Northeast Agricultural University (Harbin, China). The financial support for this project was also provided by the China Scholarship Council (Beijing, China). The authors have not stated any conflicts of interest.

\section{REFERENCES}

Ali, S., and D. J. Drucker. 2009. Benefits and limitations of reducing glucagon action for the treatment of type 2 diabetes. Am. J. Physiol. Endocrinol. Metab. 296:E415-E421. https://doi.org/10 .1152/ajpendo.90887.2008.

Bender, S. B., A. P. Mcgraw, I. Z. Jaffe, and J. R. Sowers. 2013. Mineralocorticoid receptor-mediated vascular insulin resistance: An early contributor to diabetes-related vascular disease. Diabetes 62:313-319. https://doi.org/10.2337/db12-0905.

Bordalo Tonucci, L., K. M. O. Dos Santos, C. L. De Luces Fortes Ferreira, S. M. R. Ribeiro, L. L. De Oliveira, and H. S. D. Martino. 2017. Gut microbiota and probiotics: Focus on diabetes mellitus. Crit. Rev. Food Sci Nutr. 57:2296-2309. https://doi.org/10.1080/ 10408398.2014.934438.

Chakrabarti, R., and R. Rajagopalan. 2002. Diabetes and insulin resistance associated disorders: Disease and the therapy. Curr. Sci. 83:1533-1538.

Chen, L., H. Zhao, C. Zhang, Y. Lu, X. Zhu, and Z. Lu. 2016. $\gamma$-aminobutyrate-rich yogurt fermented by Streptococcus salivarius ssp. thermophiles fmb5 appears to have anti-diabetic effect on streptozotocin-induced diabetic mice. J. Funct. Foods 20:267-275. https://doi.org/10.1016/j.jff.2015.10.030.

Chen, W. J., F. F. Song, L. G. Liu, X. Y. Qi, B. J. Xie, and Y. F. Song. 2006. Effects of mogroside extract on cellular immune functions in alloxan-induced diabetic rats. Acta Nutr. Sin. 28:221-225.

De Vadder, F., P. Kovatcheva-Datchary, D. Goncalves, J. Vinera, C. Zitoun, A. Duchampt, F. Bäckhed, and G. Mithieux. 2014. Microbiota-generated metabolites promote metabolic benefits via gut-brain neural circuits. Cell 156:84-96. https://doi.org/10.1016/ j.cell.2013.12.016.

Esser, N., S. Legrand-Poels, J. Piette, A. J. Scheen, and N. Paquot. 2014. Inflammation as a link between obesity, metabolic syndrome and type 2 diabetes. Diabetes Res. Clin. Pract. 105:141-150. https: //doi.org/10.1016/j.diabres.2014.04.006.

Fox, C. S., S. H. Golden, C. Anderson, G. A. Bray, L. E. Burke, I. H. De Boer, P. Deedwania, R. H. Eckel, A. G. Ershow, J. Fradkin, S. E. Inzucchi, M. Kosiborod, R. G. Nelson, M. J. Patel, M. Pignone, L. Quinn, P. R. Schauer, E. Selvin, and D. K. Vafiadis. 2015. Update on prevention of cardiovascular disease in adults with type 2 diabetes mellitus in light of recent evidence: A scientific statement from the American Heart Association and the American Diabetes Association. Diabetes Care 38:1777-1803. https://doi.org/10 .2337/dci15-0012.

Gao, Z., J. Yin, J. Zhang, R. E. Ward, R. J. Martin, M. Lefevre, W. T. Cefalu, and J. Ye. 2009. Butyrate improves insulin sensitivity and increases energy expenditure in mice. Diabetes 58:1509-1517. https://doi.org/10.2337/db08-1637.

Gijsbers, L., E. L. Ding, V. S. Malik, J. de Goede, J. M. Geleijnse, and S. S. Soedamah-Muthu. 2016. Consumption of dairy foods and diabetes incidence: A dose-response meta-analysis of observational studies. Am. J. Clin. Nutr. 103:1111-1124. https://doi.org/ 10.3945/ajen.115.123216.

Howard, B. V., and J. Wylierosett. 2002. Sugar and cardiovascular disease a statement for health care professionals from the Committee on Nutrition of the Council on Nutrition, Physical Activity, and Metabolism of the American Heart Association. Circulation 106:523-527. https://doi.org/10.1161/01.CIR.0000019552.77778 .04 .

International Diabetes Federation. 2017. IDF Diabetes Atlas. 8th ed. International Diabetes Federation, Brussels, Belgium. http://www .diabetesatlas.org/resourc es/2017-atlas.html.

Jia, L., D. Li, N. Feng, M. Shamoon, Z. Sun, L. Ding, H. Zhang, W. Chen, J. Sun, and Y. Q. Chen. 2017. Anti-diabetic effects of Clostridium butyricum CGMCC0313.1 through promoting the growth of gut butyrate-producing bacteria in type 2 diabetic mice. Sci. Rep. 7:7046. https://doi.org/10.1038/s41598-017-07335-0.

Karlsson, F. H., V. Tremaroli, I. Nookaew, G. Bergstrom, C. J. Behre, B. Fagerberg, J. Nielsen, and F. Backhed. 2013. Gut metagenome in European women with normal, impaired and diabetic glucose control. Nature 498:99-103. https://doi.org/10.1038/nature12198.

Kim, B., and E. L. Feldman. 2015. Insulin resistance as a key link for the increased risk of cognitive impairment in the metabolic syndrome. Exp. Mol. Med. 47:e149. https://doi.org/10.1038/emm .2015 .3 .

Kinghorn, A. D., N. Kaneda, N. I. Baek, E. J. Kennelly, and D. D. Soejarto. 1998. Noncariogenic intense natural sweeteners. Med. Res. Rev. 18:347-360. https://doi.org/10.1002/(SICI)1098 -1128(199809)18:5<347::AID-MED5>3.0.CO;2-T.

Larsen, N., F. K. Vogensen, F. W. J. van den Berg, D. S. Nielsen, A. S. Andreasen, B. K. Pedersen, W. A. Al-Soud, S. J. Sørensen, L. H. Hansen, and M. Jakobsen. 2010. Gut microbiota in human adults with type 2 diabetes differs from non-diabetic adults. PLoS One 5:e9085. https://doi.org/10.1371/journal.pone.0009085.

Li, C., L. M. Lin, F. Sui, Z. M. Wang, H. R. Huo, L. Dai, and T. L. Jiang. 2014. Chemistry and pharmacology of Siraitia grosvenorii: A review. Chin. J. Nat. Med. 12:89-102. https://doi.org/10.1016/ S1875-5364(14)60015-7.

Lin, G. P., T. Jiang, X. B. Hu, X. H. Qiao, and Q. H. Tuo. 2007. Effect of Siraitia grosvenorii polysaccharide on glucose and lipid of diabetic rabbits induced by feeding high fat/high sucrose chow. Exp. Diabetes Res. 2007:67435. https://doi.org/10.1155/2007/67435.

Liu, H., X. Qi, K. Yu, A. Lu, K. Lin, J. Zhu, M. Zhang, and Z. Sun. 2019. AMPK activation is involved in hypoglycemic and hypolipidemic activities of mogroside-rich extract from Siraitia grosvenorii (swingle) fruits on high-fat diet/streptozotocin-induced diabetic mice. Food Funct. 10:151-162. https://doi.org/10.1039/ $\mathrm{C} 8 \mathrm{FO} 01486 \mathrm{H}$.

Louis, P., K. P. Scott, S. H. Duncan, and H. J. Flint. 2007. Understanding the effects of diet on bacterial metabolism in the large intestine. J. Appl. Microbiol. 102:1197-1208. https://doi.org/10 $.1111 / \mathrm{j} .1365-2672.2007 .03322 . x$.

Lu, A. M., and Z. Y. Zhang. 1984. The genus Siraitia Merr. in China. Guihaia 4:27-33. 
Mao, B., D. Li, J. Zhao, X. Liu, Z. Gu, Y. Q. Chen, H. Zhang, and W. Chen. 2015. Metagenomic insights into the effects of fructooligosaccharides (fos) on the composition of fecal microbiota in mice. J. Agric. Food Chem. 63:856-863. https://doi.org/10.1021/ jf505156h.

Morrison, D. J., and T. Preston. 2016. Formation of short chain fatty acids by the gut microbiota and their impact on human metabolism. Gut Microbes 7:189-200. https://doi.org/10.1080/19490976 2015.1134082

Moure, A., P. Gullón, H. Domínguez, and J. C. Parajó. 2006. Advances in the manufacture, purification and applications of xylo-oligosaccharides as food additives and nutraceuticals. Process Biochem. 41:1913-1923. https://doi.org/10.1016/j.procbio.2006.05.011.

Murphy, S. P., and R. K. Johnson. 2003. The scientific basis of recent US guidance on sugars intake. Am. J. Clin. Nutr. 78:827S-833S. https://doi.org/10.1093/ajcn/78.4.827S.

Nathan, D. M., and DCCT/EDIC Research Group. 2014. The Diabetes Control and Complications Trial/Epidemiology of Diabetes Interventions and Complications study at 30 years: Overview. Diabetes Care 37:9-16.

Qi, X. Y., W. J. Chen, L. G. Liu, P. Yao, and B. J. Xie. 2006. Effect of a Siraitia grosvenori extract containing mogrosides on the cellular immune system of type 1 diabetes mellitus mice. Mol. Nutr. Food Res. 50:732-738. https://doi.org/10.1002/mnfr.200500252.

Qi, X. Y., W. J. Chen, L. Q. Zhang, and B. J. Xie. 2008. Mogrosides extract from Siraitia grosvenori scavenges free radicals in vitro and lowers oxidative stress, serum glucose, and lipid levels in alloxaninduced diabetic mice. Nutr. Res. 28:278-284. https://doi.org/10 .1016/j.nutres.2008.02.008

Qin, J., Y. Li, Z. Cai, S. Li, J. Zhu, F. Zhang, S. Liang, W. Zhang, Y. Guan, D. Shen, Y. Peng, D. Zhang, Z. Jie, W. Wu, Y. Qin, W. Xue, J. Li, L. Han, D. Lu, P. Wu, Y. Dai, X. Sun, Z. Li, A. Tang, S. Zhong, X. Li, W. Chen, R. Xu, M. Wang, Q. Feng, M. Gong, J. Yu, Y. Zhang, M. Zhang, T. Hansen, G. Sanchez, J. Raes, G. Falony, S. Okuda, M. Almeida, E. LeChatelier, P. Renault, N. Pons, J.-M. Batto, Z. Zhang, H. Chen, R. Yang, W. Zheng, S. Li, H. Yang, J. Wang, S. D. Ehrlich, R. Nielsen, O. Pedersen, K. Kristiansen, and J. Wang. 2012. A metagenome-wide association study of gut microbiota in type 2 diabetes. Nature 490:55-60. https://doi .org/10.1038/nature11450.

Qu, L., J. Ren, L. Huang, B. Pang, X. Liu, X. Liu, B. Li, and Y. Shan. 2018. Antidiabetic effects of Lactobacillus casei fermented yogurt through reshaping gut microbiota structure in Type 2 diabetic rats. J. Agric. Food Chem. 66:12696-12705. https://doi.org/10 .1021/acs.jafc.8b04874.

Shi, D., M. Zheng, Y. Wang, C. Liu, and S. Chen. 2014. Protective effects and mechanisms of mogroside $\mathrm{V}$ on lps-induced acute lung injury in mice. Pharm. Biol. 52:729-734. https://doi.org/10.3109/ 13880209.2013.867451

Shin, N. R., J. C. Lee, H. Y. Lee, M. S. Kim, T. W. Whon, M. S. Lee, and J.-W. Bae. 2014. An increase in the Akkermansia spp. population induced by metformin treatment improves glucose homeostasis in diet-induced obese mice. Gut 63:727-735. https://doi.org/10 .1136 /gutjnl-2012-303839.

Stephens, J. W., M. P. Khanolkar, and S. C. Bain. 2009. The biological relevance and measurement of plasma markers of oxidative stress in diabetes and cardiovascular disease. Atherosclerosis 202:321329. https://doi.org/10.1016/j.atherosclerosis.2008.06.006.

Suzuki, Y. A., M. Tomoda, Y. Murata, H. Inui, M. Sugiura, and Y. Nakano. 2007. Antidiabetic effect of long-term supplementation with Siraitia grosvenori on the spontaneously diabetic GotoKakizaki rat. Br. J. Nutr. 97:770-775. https://doi.org/10.1017/ S0007114507381300.

Takasaki, M., T. Konoshima, Y. Murata, M. Sugiura, H. Nishino, H. Tokuda, K. Matsumoto, R. Kasai, and K. Yamasaki. 2003. Anticarcinogenic activity of natural sweeteners, cucurbitane glycosides, from Momordica grosvenori. Cancer Lett. 198:37-42. https://doi .org/10.1016/S0304-3835(03)00285-4.

Tuepker, J. 2003. Effect of rosiglitazone treatment on nontraditional markers of cardiovascular disease in patients with type 2 diabetes mellitus. Circulation 107:e109. https://doi.org/10.1161/01.CIR $.0000067693 .46108 .2 \mathrm{D}$.

Tura, A., A. Kautzky-Willer, and G. Pacini. 2006. Insulinogenic indices from insulin and C-peptide: Comparison of beta-cell function from OGTT and IVGTT. Diabetes Res. Clin. Pract. 72:298-301. https://doi.org/10.1016/j.diabres.2005.10.005.

Umar, A., Q. U. Ahmed, B. Y. Muhammad, B. B. S. Dogarai, and S. Z. B. M. Soad. 2010. Anti-hyperglycemic activity of the leaves of Tetracera scandens Linn. Merr. (Dilleniaceae) in alloxan induced diabetic rats. J. Ethnopharmacol. 131:140-145

Unger, R. H. 1985. Glucagon physiology and pathophysiology in the light of new advances. Diabetologia 28:574-578. https://doi.org/ 10.1007/BF00281991.

Unger, R. H., E. Aguilar-Parada, W. A. Müller, and A. M. Eisentraut. 1970. Studies of pancreatic alpha cell function in normal and diabetic subjects. J. Clin. Invest. 49:837-848. https://doi.org/ 10.1172/JCI106297.

USDA. 2019. Yogurt, plain, whole milk. Agricultural Research Service National Nutrient Database for Standard Reference. Accessed March 12, 2019. https://ndb.nal.usda.gov/ndb/foods/show/01116.

Vijay-Kumar, M., J. D. Aitken, F. A. Carvalho, T. C. Cullender, S. Mwangi, S. Srinivasan, S. V. Sitaraman, R. Knight, R. E. Ley, and A. T. Gewirtz. 2010. Metabolic syndrome and altered gut microbiota in mice lacking toll-like receptor 5. Science 328:228-231. https://doi.org/10.1126/science.1179721.

Wang, Q., H. H. Qin, and W. Wang. 2010. The pharmacological research progress of Siraitiagrosvenorii. J. Guangxi Tradit. Chin. Med. Univ. 13:75-76.

Wang, W. B., Y. H. Bao, G. M. Hendricks, and M. R. Guo. 2012. Consistency, microstructure and probiotic survivability of goats' milk yoghurt using polymerized whey protein as a co-thickening agent. Int. Dairy J. 24:113-119. https://doi.org/10.1016/j.idairyj .2011.09.007.

World Health Organization. 2009. Global Health Risks: Mortality and Burden of Disease Attributable to Selected Major Risks. World Health Organization, Geneva, Switzerland.

Xu, F., D. P. Li, Z. C. Huang, F. L. Lu, L. Wang, Y. L. Huang, R.-F. Wang, G.-X. Liu, M.-Y. Shang, and S.-Q. Cai. 2015. Exploring in vitro, in vivo metabolism of mogroside $\mathrm{V}$ and distribution of its metabolites in rats by hplc-esi-it-tof-ms(n). J. Pharm. Biomed. Anal. 115:418-430. https://doi.org/10.1016/j.jpba.2015.07.024.

Zhang, X., Y. Zhao, J. Xu, Z. Xue, M. Zhang, X. Pang, X. Zhang, and L. Zhao. 2015. Modulation of gut microbiota by berberine and metformin during the treatment of high-fat diet-induced obesity in rats. Sci. Rep. 5:14405. https://doi.org/10.1038/srep14405.

Zhang, Y., X. Guo, J. Guo, Q. He, H. Li, and Y. Song. 2014. Lactobacillus casei reduces susceptibility to type 2 diabetes via microbiotamediated body chloride ion influx. Sci. Rep. 4:5654.

Zhao, L., F. Zhang, X. Ding, G. Wu, Y. Y. Lam, X. Wang, H. Fu, X. Xue, C. Lu, J. Ma, L. Yu, C. Xu, Z. Ren, Y. Xu, S. Xu, H. Shen, X. Zhu, Y. Shi, Q. Shen, W. Dong, R. Liu, Y. Ling, Y. Zeng, X. Wang, Q. Zhang, J. Wang, L. Wang, Y. Wu, B. Zeng, H. Wei, M. Zhang, Y. Peng, and C. Zhang. 2018. Gut bacteria selectively promoted by dietary fibers alleviate type 2 diabetes. Science 359:1151-1156. https://doi.org/10.1126/science.aao5774.

Zhou, G., Y. Zhang, Y. Li, M. Wang, and X. Li. 2018. The metabolism of a natural product mogroside $\mathrm{V}$, in healthy and type 2 diabetic rats. J. Chromatogr. B Analyt. Technol. Biomed. Life Sci. 1079:25-33. https://doi.org/10.1016/j.jchromb.2018.02.002.

Zhou, Y., Y. Zheng, J. Ebersole, and C. Huang. 2009. Insulin secretion stimulating effects of mogroside $\mathrm{v}$ and fruit extract of luo han kuo (siraitia grosvenori swingle) fruit extract. Yao Xue Xue Bao 44:1252.

\section{ORCIDS}

Qingfeng Ban () https://orcid.org/0000-0001-7305-8447 Xiaomeng Sun ํㅏ https://orcid.org/0000-0002-1132-8584 